\title{
Developmental Trajectories in Siblings of Children with Autism: Cognition and Language from 4 Months to 7 Years
}

\author{
Ifat Gamliel · Nurit Yirmiya · Dena H. Jaffe • \\ Orly Manor · Marian Sigman
}

Published online: 27 March 2009

(c) The Author(s) 2009. This article is published with open access at Springerlink.com

\begin{abstract}
We compared the cognitive and language development at 4, 14, 24, 36, 54 months, and 7 years of siblings of children with autism (SIBS-A) to that of siblings of children with typical development (SIBS-TD) using growth curve analyses. At 7 years, $40 \%$ of the SIBSA, compared to $16 \%$ of SIBS-TD, were identified with cognitive, language and/or academic difficulties, identified using direct tests and/or parental reports. This sub-group was identified as SIBS-A-broad phenotype (BP). Results indicated that early language scores (14-54 months), but not cognitive scores of SIBS-A-BP and SIBS-A-nonBP were significantly lower compared to the language scores of SIBS-TD, and that the rate of development was also significantly different, thus pinpointing language as a major area of difficulty for SIBS-A during the preschool years.
\end{abstract}

Keywords Autism - Siblings - Broad autism phenotype Cognition $\cdot$ Language

I. Gamliel

School of Education, Hebrew University of Jerusalem, Jerusalem, Israel

N. Yirmiya $(\square)$

Department of Psychology and School of Education, Hebrew University of Jerusalem, Mount Scopus, 91905 Jerusalem, Israel e-mail: NYirmiya@gmail.com; NuritYirmiya@huji.ac.il

D. H. Jaffe · O. Manor

School of Public Health, Hebrew University of Jerusalem, Jerusalem, Israel

M. Sigman

Departments of Psychiatry and Psychology, University

of California Los Angeles, Los Angeles, CA, USA

\section{Introduction}

Research studies on relatives of individuals with autism offer strong support for the genetic liability of autism and the broad autism phenotype (BAP). Autism is a neurodevelopmental disorder characterized by impairments in social interaction, communication (verbal and nonverbal), and behavior (repetitive and stereotyped behaviors). The BAP is generally defined as a clinical picture of milder yet qualitatively similar difficulties in cognition, communication, socialization, and behavior, namely, the same domains that are impaired in autism. No accepted or agreed-upon definitions of the BAP exist, yet more recently Dawson et al. (2007) and Hurley et al. (2007) devised the broader phenotype autism symptom scale (BPASS) and the broad autism phenotype questionnaire (BPAQ) to assess the personality and language characteristics associated with the BAP. Dawson et al. (2007) interviewed the parents about themselves and their affected child with an autism spectrum disorder (ASD), whereas Hurley et al. (2007) interviewed the parents only. Their findings support the notion that the BAP can be assessed reliably among family members of children with ASD and that the BAP involves milder yet similar difficulties in the domains of communication, relationships and restricted interests and repetitive behaviors.

Other family studies with parents and siblings of individuals with ASD concentrated on more distinct and discrete aspects of the BAP and employed various measurements including retrospective family history assessment of behavior, direct assessment with standardized general indices of developmental abilities, and/or assessment of specific aspects of development (for reviews, see Bailey et al. 1998; Bauminger and Yirmiya 2001; Lainhart 1999; Piven 1999; Schuntermann 2007; Yirmiya and Ozonoff 2007; Yirmiya et al. 2001). 
Studies with siblings of children with autism (SIBS-A) yielded contradictory evidence, with some researchers suggesting no significant differences between SIBS-A and siblings of children with typical development (SIBS-TD) or siblings of children with other diagnoses, whereas others reported lower or even better abilities among SIBS-A. Thus, no consistent findings regarding cognitive abilities emerged on general intellectual abilities such as IQ tests or reading and spelling skills (Folstein et al. 1999; Fombonne et al. 1997; Pilowsky et al. 2007), executive functions, or theory of mind abilities (Delorme et al. 2007; Dorris et al. 2004; Happé et al. 2001; Ozonoff et al. 1993; Shaked et al. 2006).

Inconsistent findings also emerged regarding the language abilities of SIBS-A. Some researchers revealed increased rates of language impairment among SIBS-A as measured by verbal IQ and expressive and receptive language tests (August 1981; Bolton et al. 1994; Fombonne et al. 1997; Leboyer et al. 1995; Plumet et al. 1995), as well as deficits in specific language aspects such as syntax, phonological processing, and pragmatics (Bishop et al. 2006, 2004; Plumet et al. 1995), verbal fluency (Hughes et al. 1999), and rapid naming (Piven and Palmer 1997). Yet, other researchers reported that the language abilities of SIBS-A did not differ from those of SIBS-TD or of siblings of children with other diagnoses (Bishop et al. 2004; Folstein et al. 1999; Gillberg et al. 1992; Happé et al. 2001; Pilowsky et al. 2003; Smalley and Asarnow 1990; Wong et al. 2006). Interestingly, Fombonne et al. (1997) and Pilowsky et al. (2003) found that SIBS-A even performed better on tests of verbal ability compared to siblings of children with developmental language disorders and siblings of children with Down's syndrome. The aforementioned studies included mostly school-aged siblings of various ages who were examined at one time point only.

Recent data from prospective studies of developmental trajectories of very young SIBS-A indicate strong evidence of early difficulties in cognitive and language development and in social engagement (Elsabbagh and Johnson 2007; Orsmond and Seltzer 2007; Yirmiya and Ozonoff 2007). Some researchers focused on antecedents and signs of ASD as early as $12-14$ months in SIBS-A who later develop autism, such as general developmental delays in cognition, language, and social engagement (Bryson et al. 2007; Landa et al. 2006, 2007; Sullivan et al. 2007; Zwaigenbaum et al. 2005) and in repetitive or atypical motor behavior (Loh et al. 2007). Other researchers focused on infant features of the BAP such as reduced affective expression and diminished gaze to the mother's eyes relative to her mouth during reciprocal social interaction (Merin et al. 2007; Cassel et al. 2007). Recent research on the developmental trajectories of young SIBS-A and their association with the BAP also indicated developmental delays in language (Gamliel et al. 2007; Toth et al. 2007) and in joint attention (Presmanes et al. 2007; Stone et al. 2007; Sullivan et al. 2007). Yirmiya and Ozonoff (2007) suggested the possibility that some features of the BAP may be transient whereas others are lasting or ongoing across development, thus calling for further investigation of the difficulties identified thus far to determine their stability over time.

In the current longitudinal study, two groups of younger SIBS-A and SIBS-TD were followed prospectively from infancy to early childhood at the ages of $4,14,24,36$, and 54 months and at 7 years. To the best of our knowledge, this is the first time that a cohort of young SIBS-A has been followed prospectively from early infancy to early childhood and that growth curve analyses are employed to examine possible differences in overall attainment of cognitive and language skills and in the rate of development of these skills. In our previous reports we examined at each time point BAP-related difficulties in cognition and language defined as at least two standard deviations below average on the cognitive and/or language measures (e.g., $\mathrm{DQ} / \mathrm{IQ}$, receptive and expressive language scores). The data revealed that although most SIBS-A were well-functioning during the preschool years based on our cognitive and language measures, a subgroup of SIBS-A manifested difficulties in these domains (Gamliel et al. 2007; Yirmiya et al. 2006, 2007). Furthermore, overall, significantly more SIBS-A had BAP-related difficulties in cognition and language during the preschool years; yet, most of the group differences disappeared by the age of 54 months, with the exception of expressive language ability, which remained an area of difficulty. Inasmuch as language may consolidate and act as a transient indicator, we were interested in the current study in examining the children after they entered school.

As some of the contradictions in the literature may be attributed to methodological issues, namely the different ages of the participants within and between studies, the different assessment methods used, the variety in comparison groups, and the various definitions of the BAP employed. In the current study, all siblings were examined at the same age at each time point, and our comparison group was well matched at the beginning of the study. Use of a well-matched comparison group is important because recent research has revealed that some studies of SIBS-A (i.e., head circumference) yielded different results when norms were used as reference than when using a comparison group of low-risk infants (with no family history of autism spectrum disorder). Whereas Elder et al. (2008) found that the head circumference values of SIBS-A at 12 months were significantly higher than the norms provided by the Center for Disease Control, Zwaigenbaum et al. (2008) reported non-significant differences in head 
circumference when comparing SIBS-A to a group of matched low-risk infants.

Beyond our matching procedure, to further account for discrepancies due to methodological issues, we decided to examine BAP-related difficulties in cognition and language in SIBS-A at age 7 years using both direct assessment measures (e.g., developmental, cognitive, and language tests) as well as parental reports. Recent research have established the use of informant-base measures in the examination of the BAP related difficulties (i.e., Constantino and Todd 2005; Dawson et al. 2007; Hurley et al. 2007) suggesting the importance of reports to direct assessments.

Using these different assessment measures at age 7 years, we then "looked back" and examined these children's developmental trajectories back in their preschool years (4-54 months) using growth curve analysis, a method well suited for developmental studies and longitudinal data with several waves of data collection (Singer and Willett 2003). Using this method, we examined differences in developmental trajectories at the aggregate level of the SIBS-A and SIBS-TD groups, as well as the nature and rate of change over time (slope). Based on previous findings, we hypothesized that the developmental trajectories of SIBS-A who now demonstrated BAP-related difficulties in cognition and language at age 7 would differ from the trajectories of those SIBS-A who did not demonstrate those BAP-related difficulties at age 7, and also compared to SIBS-TD. We were unsure whether SIBS-A who demonstrated no BAP-related difficulties in cognition and language at age 7 would nonetheless show different developmental trajectories compared to SIBS-TD.

\section{Method}

Participants

The SIBS-A group in the current study comprised 37 children (14 girls/23 boys) who have an older sibling with autism. The longitudinal study was conducted at the ages of 4, 14, 24, 36, 54 months, and 7 years (see Table 1). Infants SIBS-A who were recruited prior to the 14-month testing interval were enrolled between the ages of 0 and 9 months $(n=31)$. At the time of enrollment, parents reported that all the participants were developing well and free of parental concern.

All probands (10 girls/27 boys) with autism had a previous diagnosis of Autistic Disorder made by independent clinicians. However, for the purpose of this study, two trained clinicians who were blind to all other study procedures confirmed diagnoses using the autism diagnostic observation schedule-generic (ADOS-G; Lord et al. 2000) and/or for those probands recruited before the translation of this measure to Hebrew, the autism diagnostic interview-revised (ADI-R; Rutter et al. 2003). All probands were re-diagnosed with Autistic Disorder. In addition, probands' IQ/DQ was assessed with a standard IQ test appropriate for the proband's age and/or developmental abilities, i.e., Bayley Scales of Infant Development-2nd edition (Bayley 1993); Kaufman assessment battery for children (Kaufman and Kaufman 1983); or Wechsler intelligence scale for children-3rd edition (Wechsler 1991). Nine of the 37 probands with autism were classified as high functioning (IQ and/or daily living skills scores $>70$ ), whereas the remaining 28 displayed IQ and daily living skills scores below 70 .

Inclusion criteria for this group comprised intact families who had a child with autism and a younger sibling. Exclusion criteria were medical conditions associated with autism such as Fragile $\mathrm{X}$ and Tuberous sclerosis in the probands. Families were recruited through treatment centers, special education schools, and the national organization for children with autism in Israel, and through families of children with autism.

The SIBS-TD group comprised 47 children (17 girls/30 boys) who have an older sibling with typical development and were seen at the ages of 4, 14, 24, 36, 54 months, and 7 years (see Table 1). Families were recruited from

Table 1 Group characteristics for SIBS-A and SIBS-TD from 4 months to 7 years

\begin{tabular}{|c|c|c|c|c|c|c|c|c|c|c|}
\hline \multirow[t]{3}{*}{ No. months } & \multicolumn{5}{|c|}{ NNSIBS-A } & \multicolumn{5}{|c|}{ SIBS-TD } \\
\hline & \multirow[t]{2}{*}{$n$} & \multirow[t]{2}{*}{ Female:Male } & \multicolumn{3}{|c|}{ Age in months } & \multirow[t]{2}{*}{$n$} & \multirow[t]{2}{*}{ Female:Male } & \multicolumn{3}{|c|}{ Age in months } \\
\hline & & & $M$ & SD & Range & & & $M$ & SD & Range \\
\hline 4 & 21 & $8: 13$ & 4.48 & .81 & $4-6$ & 47 & $17: 30$ & 4.26 & .57 & $4-6$ \\
\hline 14 & 30 & $11: 19$ & 14.13 & .29 & $14-15$ & 46 & $17: 29$ & 14.22 & .39 & $14-16$ \\
\hline 24 & 38 & $15: 23$ & 24.24 & .42 & $24-25$ & 46 & $17: 29$ & 24.20 & .45 & $24-26$ \\
\hline 36 & 39 & $15: 24$ & 36.47 & .64 & $35-38$ & 46 & $17: 29$ & 36.39 & .75 & $36-39$ \\
\hline 54 & 39 & $14: 25$ & 54.78 & .92 & $54-57$ & 45 & $16: 29$ & 54.66 & 1.18 & $54-59$ \\
\hline 84 & 37 & $14: 23$ & 84.57 & 1.39 & 83-91 & 37 & $16: 21$ & 84.30 & .62 & $83-86$ \\
\hline
\end{tabular}


maternity wards in Jerusalem. Inclusion criteria for families in this group were intact families with a newborn and an older child with typical development, with no history of any learning and/or emotional difficulties according to parental report. In the process of recruitment, we ended up with more SIBS-TD than SIBS-A.

The two groups were matched at 4 months according to chronological age, sex, birth order, number of children in the family, sex of the older proband, and temperament profile (ICQ: infant characteristics questionnaire; Bates et al. 1979). SIBS-A who joined the study after the age of 4 months, were matched to SIBS-TD according to the aforementioned variables, as best as possible. Parents' age, ethnicity, income, and education level did not significantly differ between the two groups at the age of 4 months. At each age, we reexamined these background variables and found no significant differences between the groups.

Up to age 7, our attrition rates were relatively low: 4 families from the SIBS-A and 10 from the SIBS-TD group (Table 1) did not participate in all time points.

Attrition occurred mainly due to relocation and/or technical difficulties such as when the families were unwilling to commute. Please see Table 1 for group characteristics. Only one sibling from the SIBS-A group was diagnosed with Autistic Disorder at age 24 months and his data was thus excluded from all analyses. Other children in our sample who had developmental concerns were referred to full evaluation but none were diagnosed with any ASD. For more details regarding the early development of the siblings in our sample, please see Yirmiya et al. (2006, 2007).

\section{Measures}

The various measures administered at each age are presented in Table 2.

\section{Cognition}

Bayley Scales of Infant Development-2nd Edition The bayley scales of infant development-2nd edition (BSIDII; Bayley 1993) is a standardized, individually administered test designed to assess the developmental level of infants and toddlers between the ages of 1-42 months. The mental developmental index (MDI) was calculated and used as the cognitive ability measure at 4, 14, and 24 months. The MDI has a mean standard score of 100 and a standard deviation of 15 .

Kaufman Assessment Battery for Children The Kaufman assessment battery for children (K-ABC; Kaufman and Kaufman 1983) is a standardized, individually administered intelligence test designed for children with a mean standard score of 100 and a standard deviation of 15 . The $\mathrm{K}-\mathrm{ABC}$ mental processing score was calculated at 36 and 54 months, and is the most updated standardized intelligence test in Hebrew for these ages.

Wechsler Intelligence Scale for Children The Wechsler intelligence scale for children (WISC-III; Wechsler 1991) is a standardized, individually administered test designed to assess intellectual abilities of children between the ages of 6-16 years. Verbal IQ and Performance IQ were calculated as well as Full IQ score (all have a mean of 100, standard deviation of 15). The Full IQ score was used at age 7 years to indicate cognitive ability.

Wide Range Achievement Tests-3rd Edition (WRAT-III) The wide range achievement tests-3rd edition (WRAT; Jastak and Wilkinson 1993) is a standardized, individually administered measure for the assessment of children's achievements in three fundamental academic skills: reading, spelling, and arithmetic. Siblings' scores were summed

Table 2 Procedures employed for siblings by age

\begin{tabular}{|c|c|c|c|c|c|c|}
\hline \multirow[t]{2}{*}{ Procedure } & \multicolumn{6}{|c|}{ Age in months } \\
\hline & 4 & 14 & 24 & 36 & 54 & 84 \\
\hline \multicolumn{7}{|l|}{ Cognition } \\
\hline Bayley scales of infant development (BSID-II) & $\sqrt{ }$ & $\sqrt{ }$ & $\sqrt{ }$ & & & \\
\hline Kaufman assessment battery for children (K-ABC) & & & & $\sqrt{ }$ & $\sqrt{ }$ & \\
\hline Wechsler intelligence scale for children (WISC-III) & & & & & & $\sqrt{ }$ \\
\hline Wide range achievement test (WRAT-III) & & & & & & $\sqrt{ }$ \\
\hline \multicolumn{7}{|l|}{ Language } \\
\hline BSID-II: language developmental age & & $\sqrt{ }$ & & & & \\
\hline Reynell developmental language scales (RDLS) & & & $\sqrt{ }$ & & & \\
\hline Clinical evaluation of language fundamentals-preschool (CELF-P) & & & & $\sqrt{ }$ & $\sqrt{ }$ & \\
\hline Clinical evaluation of language fundamentals (CELF-III) & & & & & & $\sqrt{ }$ \\
\hline
\end{tabular}


for each domain separately yielding scaled scores for the corresponding chronological age. All three domains have a mean score of 100 and a standard deviation of 15 .

\section{Language}

Bayley Scales of Infant Development-2nd Edition: Language Developmental Age In addition to the BSID-II mental and motor scores, a language developmental age score was calculated at 14 months and was used as an index for both receptive and expressive language abilities. The developmental language age scores based on this individually administered test were transformed to standardized scores.

Reynell Developmental Language Scales The reynell developmental language scales (RDLS; Reynell and Grubber 1990) provides both quantitative and qualitative assessments of expressive language and verbal comprehension. Each of these scales has a mean score of 100 with a standard deviation of 15 . Based on this individually administered test at 24 months, the RDLS receptive and expressive scores were calculated as well as an additional average score of the receptive and expressive scores.

\section{Clinical Evaluation of Language Fundamentals-Pre-} school The clinical evaluation of language fundamentalspreschool (CELF-Preschool; Wiig et al. 1992) is designed for identification, diagnosis, and follow-up evaluations of language abilities in preschool children. This individually administered test is standardized for children between the ages of 3-6 years. Used in our study at the ages of 36 and 54 months, the test provided scaled scores for receptive and expressive verbal abilities as well as a total scale score for all subtests combined. All three scaled scores have a mean score of 100 and a standard deviation of 15 .

Clinical Evaluation of Language Fundamentals-3rd Edition The clinical evaluation of language fundamentals3rd edition (CELF-III; Semel et al. 1995) is a standardized, individually administered test designed to assess language abilities of individuals between the ages of 6 and 21 years. We used it at the 7-year interval. In addition to the total language score, the CELF-III yielded two subscales: receptive language score and expressive language score. All three have a mean score of 100 and a standard deviation of 15 .

All tests with the exception of the K-ABC have been translated to Hebrew and are ordinarily used in clinical evaluations but have not been standardized in Israel. Given the lack of available standardized tests and the group comparison design of the current study in which the same tests were administered to the children at the same ages, this was the best possible approach available.

\section{Family History Questionnaire}

To screen for siblings' school-related difficulties we used an adaptation of the family history interview (FHI; Bolton et al. 1994; J. Piven, 1995 personal communication; Piven et al. 1990) and translated into Hebrew by N. Yirmiya with permission from S. Folstein and J. Piven. Originally the FHI is an interview carried out with parents who respond about themselves in order to assess the presence of developmental abnormalities in their own history. Given that we were interested in the siblings, we adapted this instrument so that the parents responded about their children who are the younger siblings of their affected child. For the purpose of the current report and to supplement direct testing results at age 7 years, we looked at the cluster of communication and learning difficulties and identified children whose parents reported on current learning difficulties and disabilities including reading, writing and mathematics. (This questionnaire is available per request from NY).

\section{Demographic Information}

Background details including the number of children, family income, parents' employment status, and parents' education were collected at each age.

\section{Procedure}

Participating families were contacted in close proximity to the child's designated age. Informed consent was obtained from parents of all participants before any research procedures were conducted. The sessions at 4, 14, 24, 36, and 54 months are described in Shaked et al. (2006), Yirmiya et al. (2006), and (2007). At age 7 years, each participant was seen individually for two sessions, lasting about 120 min each and separated by about a one-week interval. The WISC-III and some additional procedures were administered during one session, and the CELF-III, the WRAT-III and some additional procedures were administered during the other session. The order of the sessions was randomly assigned for the two groups. Parent report questionnaires (FHQ, demographic information, and other questionnaires) were handed to parents in the first session for completion at home and were collected at the next session. Evaluation procedures were compatible with children's attention span and activity level. Breaks were given as often as needed. Parents were reimbursed for travel and received a detailed report summarizing their child's performance. 


\section{Statistical Analysis}

Multilevel growth curve analyses (Kristjansson et al. 2007) were used to describe the developmental course in cognition and language development among SIBS-A and SIBSTD. Models were fitted using the MLwiN software package (version 2.0) that allowed for unbalanced and missing data. Two-level growth models were used to assess within-person (Level 1) and between-person (Level 2) variation over time. Age in months was used as an indicator of time and, in the growth models, was tested as a linear and quadratic term. Interaction between sibling groups and age was assessed to detect a difference in developmental course relative to the referent group (SIBS-TD group).

\section{Results}

Childhood Outcome: Siblings Identified with BAPRelated Difficulties at 7 Years

At age 7 years, siblings with difficulties related to the manifestations of the BAP were identified using parental report on the FHQ and/or test scores on the WISC-III (Full IQ, Verbal IQ, Performance IQ) and/or the CELF-III (receptive, expressive, total language scores) and/or the WRAT-III (reading, spelling, arithmetic scores). BAP manifestations were defined as parent-reported difficulties on the FHQ and/or scores of at least 1.5 standard deviations below average on the cognitive and/or language measures. Using these criteria, we identified 15 of the 37 SIBS-A $(40.54 \%)$ as revealing BAP-related difficulties. Eight siblings revealed difficulties on the cognitive and/or language standardized measures, and 11 siblings' revealed difficulties according to parental reports (four siblings' revealed difficulties on both parental reports and test scores). In contrast, only 6 of the 37 SIBS-TD (16.22\%) revealed BAP-related difficulties ( 4 based on test scores only and 2 based on parental reports only). This difference was significant, $\chi_{(1 / 74)}^{2}=5.39, p=.02$.

To account for methodological considerations, we defined three models for investigating the subgroup of siblings from the SIBS-A group who were identified as showing BAP-related difficulties at 7 years (henceforth: SIBS-A-BP). Model 1 comprised all SIBS-A-BP identified by both parental reports (FHQ) and test scores (WISC-III and/or CELF-III andlor WRAT-III) at age 7 years. Model 2 comprised all SIBS-A-BP identified only by parent reports. Model 3 comprised all SIBS-A-BP identified only by test scores.

Finally, concerning the SIBS-TD group, we conducted two sets of preliminary analyses, one including the 6 SIBSTD identified as showing BAP-related difficulties at
7 years, and one excluding those six siblings. Results were the same. Nevertheless, on the side of caution, in order to ensure that only typically developing children would serve as comparisons, our final analyses only included the SIBSTD who did not reveal difficulties at 7 years (i.e., $n=31$ ).

Thus, we employed multilevel growth curve analyses to examine the cognitive and language developmental trajectories from the preschool years, i.e., 4-54 months, regarding the three groups identified at 7 years: SIBS-ABP (using three models), SIBS-A-nonBP (the remaining SIBS-A), and SIBS-TD.

\section{Cognition}

A growth curve model was used to assess changes in cognition (DQ/IQ scores) over five points in time: 4, 14, 24, 36, and 54 months (Table 3). The SIBS-A-BP group was identified once using Model 1, once using Model 2, and once using Model 3, while using the SIBS-TD group as a reference category. The models predicted trajectories in cognitive development from 4 to 54 months and enabled us to estimate group differences in either the intercept or the rate of change.

The resultant growth curves yielded no significant differences between the three groups' cognitive scores over time (4-54 months), for any of the three models (Table 3). Furthermore, the growth curves over time for the overall pattern of cognitive development showed a similar U-shape and were parallel for the three groups, thus indicating a similar rate of change over the years (Figs. 1, 2, 3).

\section{Language (Total, Receptive, and Expressive)}

A growth curve model was used to assess changes in language (total, receptive, and expressive language scores) over four points in time: 14, 24, 36, and 54 months (Tables 4, 5, 6). We examined linguistic differences among the three groups using three models, as presented for the cognitive scores. The models predicted trajectories in language development from 14 to 54 months. The overall pattern of language development followed a U-shape for the total and expressive language scores (Figs. 4, 7, 10, 6, 9,12 , respectively) and followed a linear shape for the growth in receptive language scores (Figs. 5, 8, 11).

\section{Model 1}

In Model 1, we examined linguistic differences among the following three groups: the SIBS-A-BP group identified using both parental reports and test scores at 7 years; the SIBS-A-nonBP group; and the SIBS-TD group. The resultant growth curves demonstrated the same results for the total, receptive, and expressive language scores: the 
Table 3 Cognition

$\begin{array}{lll}\text { Model } 1 & \text { Model 2 } & \text { Model 3 } \\ \text { Parent reports and test scores } & \text { Parent reports only } & \text { Test scores only } \\ \text { Coefficient (SE) } & \text { Coefficient (SE) } & \text { Coefficient (SE) }\end{array}$

\begin{tabular}{llll}
\hline Variables & & & \\
Intercept & $112.00(2.19)^{*}$ & $119.90(2.21)^{*}$ & $112.00(2.16)^{*}$ \\
Age & $-.47(.13)^{*}$ & $-.46(.13)^{*}$ & $-.48(.13)^{*}$ \\
$\quad$ Age $\times$ age & $.01(.002)^{*}$ & $.01(.002)^{*}$ & $.01(.002)^{*}$ \\
SIBS-TD (reference) & $-7.90(4.54)$ & $-10.46(5.73)$ & $-7.29(5.67)$ \\
vs. SIBS-A-BP & $-1.63(3.20)$ & $-2.18(3.10)$ & $-2.75(3.02)$ \\
vs. SIBS-A-nonBP & $-.02(.10)$ & $.11(.13)$ & $-.16(.13)$ \\
Age $\times$ SIBS-A-BP & $-.01(.08)$ & $-.04(.07)$ & $-.02(.07)$ \\
Age $\times$ SIBS-A-nonBP & & & $-4.54(5.85)$ \\
SIBS-A-nonBP (reference) & $-6.27(4.87)$ & $.15(.13)$ & $-.17(.14)$ \\
vs. SIBS-A-BP & $-.01(.11)$ & $112.50(9.50)$ & $113.20(9.50)$ \\
Age $\times$ SIBS-A-BP & & $70.80(15.30)$ & $61.40(13.90)$ \\
Variance & $113.40(9.60)$ & $2,844.30$ & $2,837.90$ \\
Level 1-within-person & $65.00(14.50)$ & \\
Level 2-between-person & $2,842.00$ & & \\
-2 log likelihood & &
\end{tabular}

$* p<.05$

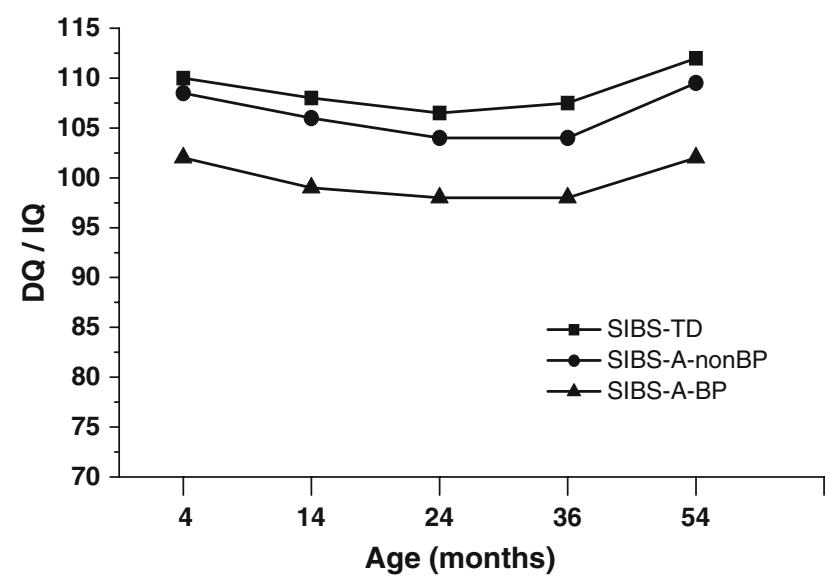

Fig. 1 Cognition based on parent reports and test scores (Model 1)

SIBS-A-BP language scores were significantly lower on average by $10.77-11.61$ points $(p<.05)$ relative to the SIBS-TD (see Model 1 in Tables 4, 5, 6). No other significant differences emerged between the three groups, for any of the three language scores, and their growth curves over time were similar in shape and parallel, thus indicating a similar rate of change over the years (Figs. 4, 5, 6).

\section{Model 2}

In Model 2, we examined linguistic differences among the following three groups: the SIBS-A-BP group identified

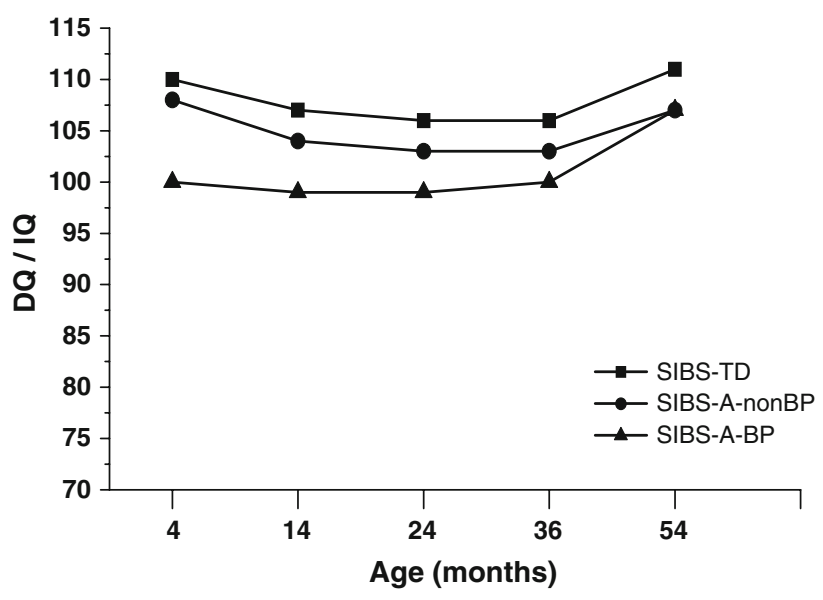

Fig. 2 Cognition based on parent reports only (Model 2)

using only parental reports at 7 years; the SIBS-A-nonBP group; and the SIBS-TD group. The resultant growth curves demonstrated the same results for the three language scores (total, receptive, and expressive). SIBS-A-BP were significantly lower on average by 15.45-20.79 points $(p<.05)$ relative to the SIBS-A-nonBP and the SIBS-TD (see Model 2 in Tables 4, 5, 6). Furthermore, the SIBS-ABP also developed differently, i.e., had a different rate of change over time relative to the SIBS-TD, as observed in the statistical significance of the Age $\times$ SIBS-A-BP variable (Model 2 in Tables 4, 5,6) as well as observed in their growth curves (Figs. 7, 8, 9). 


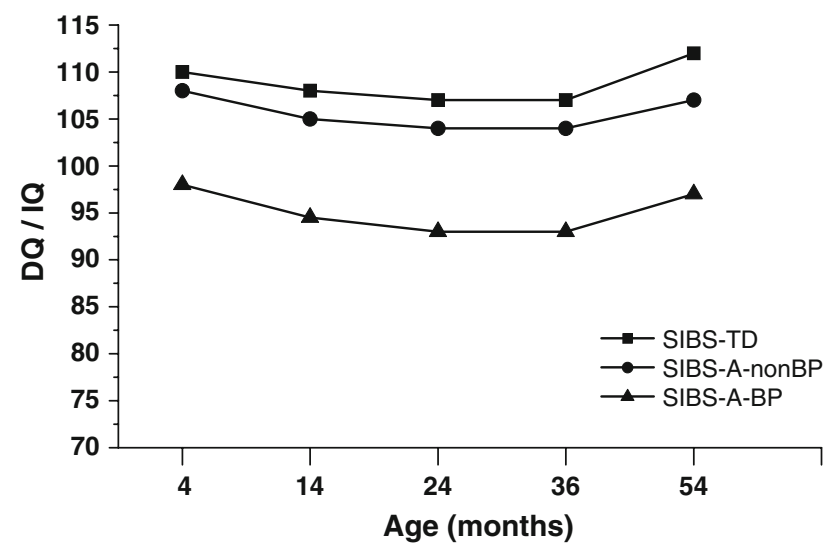

Fig. 3 Cognition based on test scores only (Model 3)

\section{Model 3}

Finally, in Model 3, we examined linguistic differences among the following three groups: the SIBS-A-BP group identified using only test scores at 7 years; the SIBS-AnonBP group; and the SIBS-TD group. The resultant growth curves demonstrated the same results for the three language scores (total, receptive, and expressive). SIBS-AnonBP were significantly lower on average by 8.07-9.89 points $(p<.05)$ relative to the SIBS-TD (see Model 3 in Tables 4, 5, 6). Furthermore, the SIBS-A-nonBP also developed differently over time relative to the SIBS-TD, as observed in the statistical significance of the Age $\times$
SIBS-A-nonBP variable (Model 3 in Tables 4, 5, 6) as well as observed in their growth curves (Figs. 10, 11, 12).

\section{Discussion}

The cognitive and language skills of SIBS-A were compared to those of SIBS-TD from 4 months to 7 years using growth curve analyses. At age 7 years, compared to SIBSTD, significantly more SIBS-A revealed BAP-related difficulties, i.e., performance of at least 1.5 standard deviations below average on the cognitive and/or linguistic measures and/or parent-reported difficulties. Thus, about $40 \%$ of the SIBS-A were identified as manifesting cognitive, language, and/or learning difficulties as measured both by parental reports and standardized test scores.

This finding indicated a significant increase in the number of SIBS-A identified with BAP-related difficulties in cognition and language compared to our previous findings in the preschool years (Gamliel et al. 2007; Yirmiya et al. 2006, 2007). This increase might be related to the beginning of the school period when cognitive and language abilities are starting to consolidate and difficulties appear as the child first faces academic tasks and requirements. In support of this explanation, a significant increase was also apparent in the number of SIBS-TD identified with difficulties at age 7 years, whereas almost no SIBS-TD was identified in the preschool years. Furthermore, similarly to our findings, studies of older

Table 4 Total language

\begin{tabular}{|c|c|c|c|}
\hline & $\begin{array}{l}\text { Model } 1 \\
\text { Parent reports and test scores } \\
\text { Coefficient (SE) }\end{array}$ & $\begin{array}{l}\text { Model } 2 \\
\text { Parent reports only } \\
\text { Coefficient (SE) }\end{array}$ & $\begin{array}{l}\text { Model } 3 \\
\text { Test scores only } \\
\text { Coefficient (SE) }\end{array}$ \\
\hline \multicolumn{4}{|l|}{ Variables } \\
\hline Intercept & $108.60(4.19)^{*}$ & $107.90(4.16)^{*}$ & $108.70(4.16)^{*}$ \\
\hline Age & $.80(.25)^{*}$ & $.74(.25)^{*}$ & $-.81(.25)^{*}$ \\
\hline Age $\times$ age & $.03(.01)^{*}$ & $.02(.01)^{*}$ & $.03(.01)^{*}$ \\
\hline \multicolumn{4}{|l|}{ SIBS-TD (reference) } \\
\hline vs. SIBS-A-BP & $-11.18(5.53)^{*}$ & $-20.79(6.90)^{*}$ & $-1.50(6.93)$ \\
\hline vs. SIBS-A-nonBP & $-6.18(4.04)$ & $-4.98(3.89)$ & $-9.00(3.83)^{*}$ \\
\hline Age $\times$ SIBS-A-BP & $.14(.13)$ & $.38(.15)^{*}$ & $.13(.16)$ \\
\hline Age $\times$ SIBS-A-nonBP & $.13(.10)$ & $.07(.09)$ & $.19(.09)^{*}$ \\
\hline \multicolumn{4}{|l|}{ SIBS-A-nonBP (reference) } \\
\hline vs. SIBS-A-BP & $-5.00(5.90)$ & $-15.82(7.09)^{*}$ & $-7.51(7.12)$ \\
\hline Age $\times$ SIBS-A-BP & $.01(.14)$ & $.31(.16)^{* *}$ & $-.32(.16)$ \\
\hline \multicolumn{4}{|l|}{ Variance } \\
\hline Level 1 -within-person & $114.20(11.00)$ & $111.70(10.70)$ & $112.90(10.80)$ \\
\hline Level 2-between-person & $79.10(17.70)$ & $82.30(18.10)$ & $79.10(17.60)$ \\
\hline$-2 \log$ likelihood & $2,359.30$ & $2,356.10$ & $2,356.40$ \\
\hline
\end{tabular}


Table 5 Receptive language

\begin{tabular}{llll}
\hline & $\begin{array}{l}\text { Model 1 } \\
\text { Parent reports and test scores } \\
\text { Coefficient (SE) }\end{array}$ & $\begin{array}{l}\text { Model 2 } \\
\text { Parent reports only } \\
\text { Coefficient (SE) }\end{array}$ & $\begin{array}{l}\text { Model 3 } \\
\text { Test scores only } \\
\text { Coefficient (SE) }\end{array}$ \\
\hline Variables & & & \\
Intercept & $99.10(2.82)^{*}$ & $99.10(2.82)^{*}$ & $99.10(2.82)^{*}$ \\
Age & $.16(.07)^{*}$ & $.16(.07)^{*}$ & $.16(.07)^{*}$ \\
Age $\times$ age & NS & NS & NS \\
SIBS-TD (reference) & & & $-1.63(7.94)$ \\
vs. SIBS-A-BP & $-11.61(6.34)^{*}$ & $-20.37(7.92)^{*}$ & $-9.89(4.39) *$ \\
vs. SIBS-A-nonBP & $-7.03(4.63)$ & $-5.86(4.41)$ & $.17(.19)$ \\
Age $\times$ SIBS-A-BP & $.13(.15)$ & $.07(.11)$ & $.20(.11)^{*}$ \\
Age $\times$ SIBS-A-nonBP & $.13(.11)$ & & $-8.19(8.14)$ \\
SIBS-A-nonBP (reference) & & $-15.95(8.16)^{* *}$ & $-.36(.19)$ \\
$\quad$ vs. SIBS-A-BP & $-5.25(6.77)$ & $.32(.19)$ & $162.10(15.50)$ \\
Age $\times$ SIBS-A-BP & $.02(.16)$ & & $83.80(20.60)$ \\
Variance & & $161.50(15.50)$ & $2,463.80$ \\
Level 1-within-person & $163.90(15.60)$ & $2,465.20$ & \\
Level 2-between-person & $84.40(20.80)$ & &
\end{tabular}

Table 6 Expressive language

\begin{tabular}{llll}
\hline & $\begin{array}{l}\text { Parent reports and test scores } \\
\text { Model 1 } \\
\text { Coefficient (SE) }\end{array}$ & $\begin{array}{l}\text { Model 2 } \\
\text { Parent reports only } \\
\text { Coefficient (SE) }\end{array}$ & $\begin{array}{l}\text { Model 3 } \\
\text { Test scores only } \\
\text { Coefficient (SE) }\end{array}$ \\
\hline Variables & & & \\
Intercept & $123.55(4.07)^{*}$ & $122.90(4.06)^{*}$ & $123.80(4.06)^{*}$ \\
Age & $-2.13(.24)^{*}$ & $-2.09(.24)^{*}$ & $-2.15(.24)^{*}$ \\
Age $\times$ age & $-.06(.01)$ & $-.06(.01)$ & $-.06(.01)$ \\
SIBS-TD (reference) & & $-19.75(6.70)^{*}$ & $-1.84(6.77)$ \\
vs. SIBS-A-BP & $-10.77(5.39)^{*}$ & $-4.30(3.75)$ & $-8.07(3.75)^{*}$ \\
vs. SIBS-A-nonBP & $-5.33(3.94)$ & $.36(.15)^{*}$ & $-.08(.15)$ \\
Age $\times$ SIBS-A-BP & $.14(.12)$ & $.07(.09)$ & $.17(.09)^{*}$ \\
Age $\times$ SIBS-A-nonBP & $.12(.12)$ & & $-6.23(6.95)$ \\
SIBS-A-nonBP (reference) & & $-15.45(6.88)^{*}$ & $-.25(.16)$ \\
vs. SIBS-A-BP & $-5.44(5.74)$ & $.29(.16)^{* *}$ & $107.90(10.30)$ \\
Age $\times$ SIBS-A-BP & $.03(.13)$ & $106.50(17.20)$ & $76.90(17.00)$ \\
Variance & & $78.40(17.20)$ & $2,359.50$ \\
Level 1-within-person & $108.68(10.38)$ & $2,457.40$ & \\
Level 2-between-person & $76.11(16.91)$ & & \\
-2 log likelihood & $2,360.61$ & &
\end{tabular}

SIBS-A, during school age and adolescence, also revealed cognitive and language difficulties regarding general intellectual abilities (i.e., Boutin et al. 1997; Ozonoff et al. 1993; Piven et al. 1990). It is also important to consider the methodological differences regarding the inclusion of parental report in our criteria compared to our previous operationalization in the preschool years, which included only test scores.
The current examination of early developmental trajectories for those siblings identified with BAP-related difficulties in cognition and language at 7 years supports the growing evidence suggesting that, as a group, younger SIBS-A manifest deficits in language but not cognitive abilities. As language is one of the domains most severely affected in autism, language difficulties may indeed be part of the broad phenotype in young SIBS-A (Stone et al. 


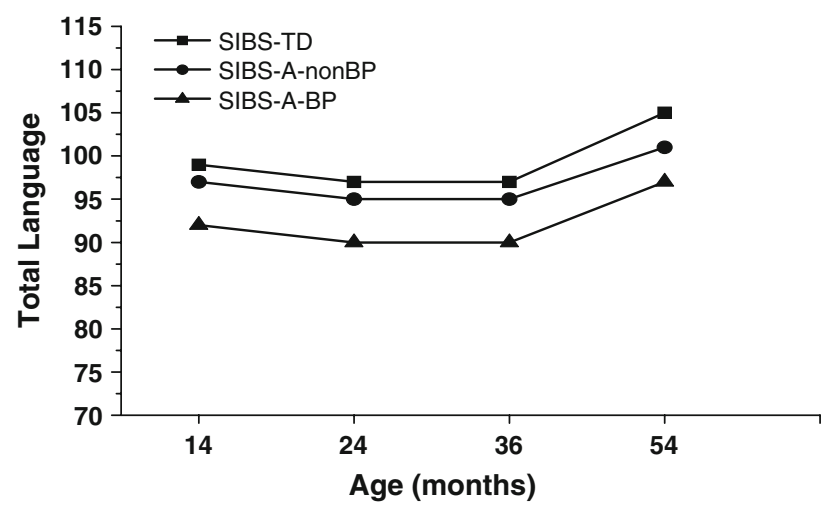

Fig. 4 Total language based on parent reports and test scores (Model 1)

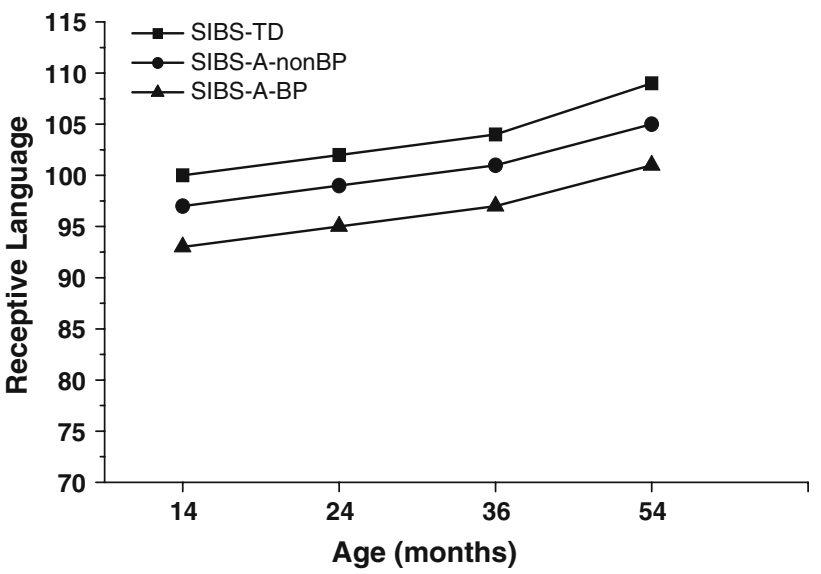

Fig. 5 Receptive language based on parent reports and test scores (Model 1)

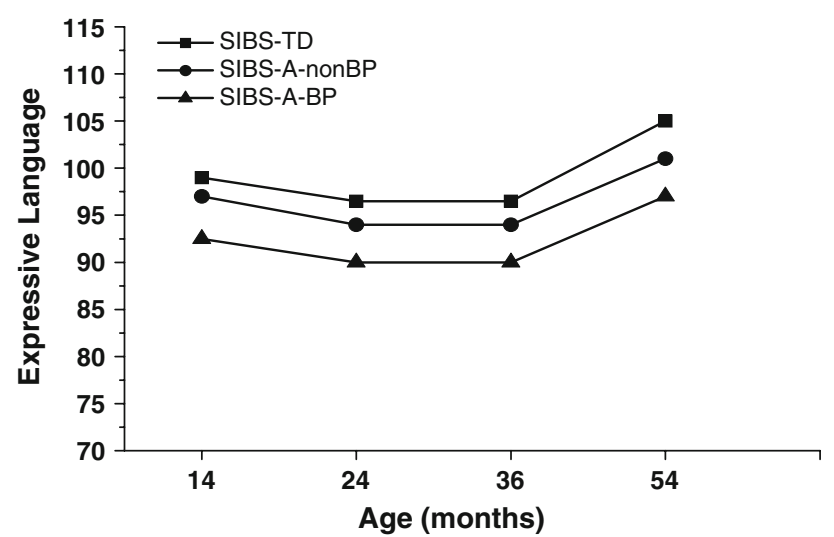

Fig. 6 Expressive language based on parent reports and test scores (Model 1)

2007; Toth et al. 2007) and in parents (Dawson et al. 2007; Hurley et al. 2007). Interestingly, for some of the SIBS-A$\mathrm{BP}$ identified at 7 years, difficulties were detected for the first time ( $n=10)$, whereas for the other five SIBS-A-BP, difficulties were evidenced earlier as well. This is in sharp

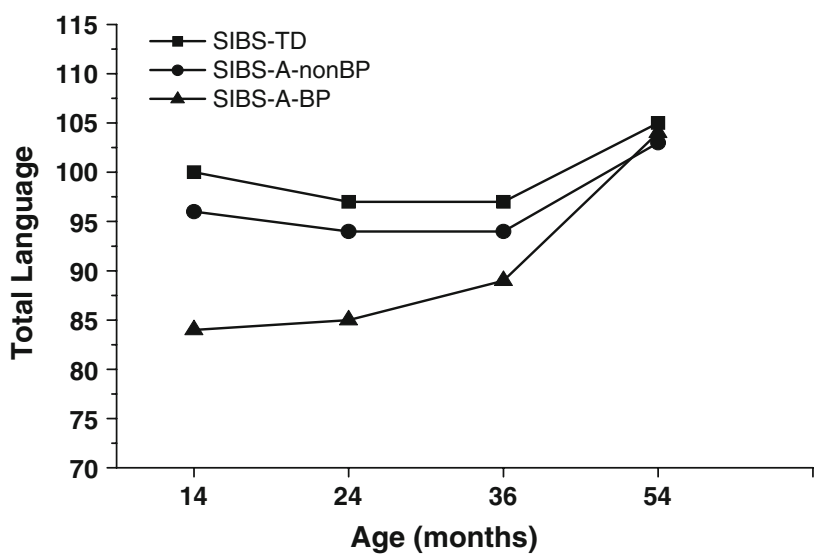

Fig. 7 Total language based on parent reports only (Model 2)

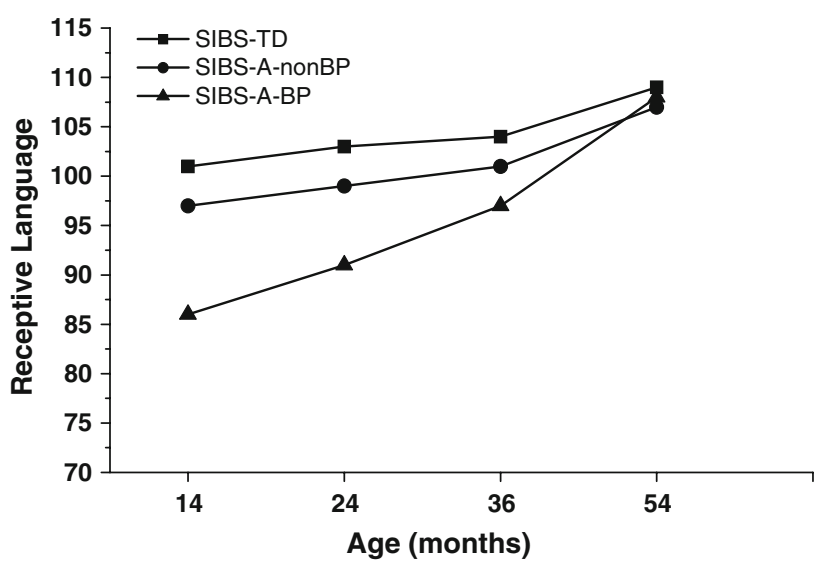

Fig. 8 Receptive language based on parent reports only (Model 2)

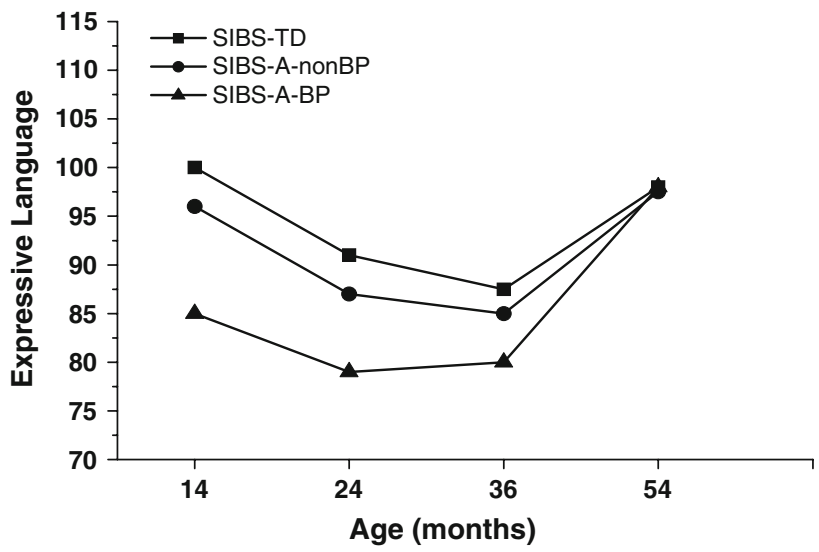

Fig. 9 Expressive language based on parent reports only (Model 2)

contrast to the fact that none of the SIBS-TD who was identified at 7 years manifested any earlier difficulties during the preschool years. Thus, it might be suggested that, for some of the SIBS-A, a "sleeper effect" could be operating and, for others, earlier language difficulties may reappear as learning difficulties during later school years. 


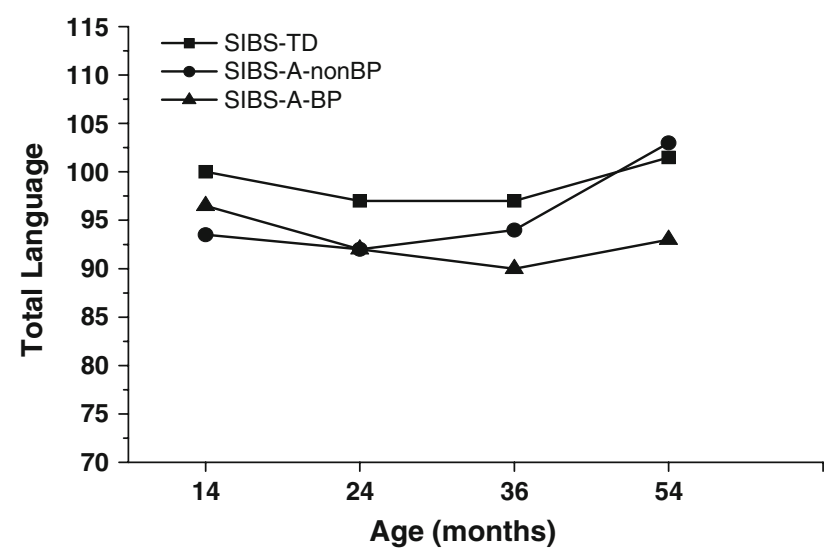

Fig. 10 Total language based on test scores only (Model 3)

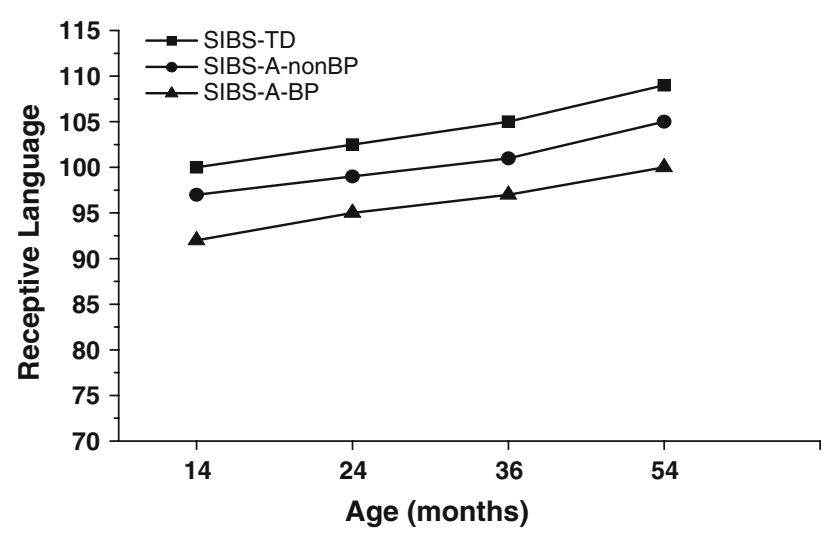

Fig. 11 Receptive language based on test scores only (Model 3)

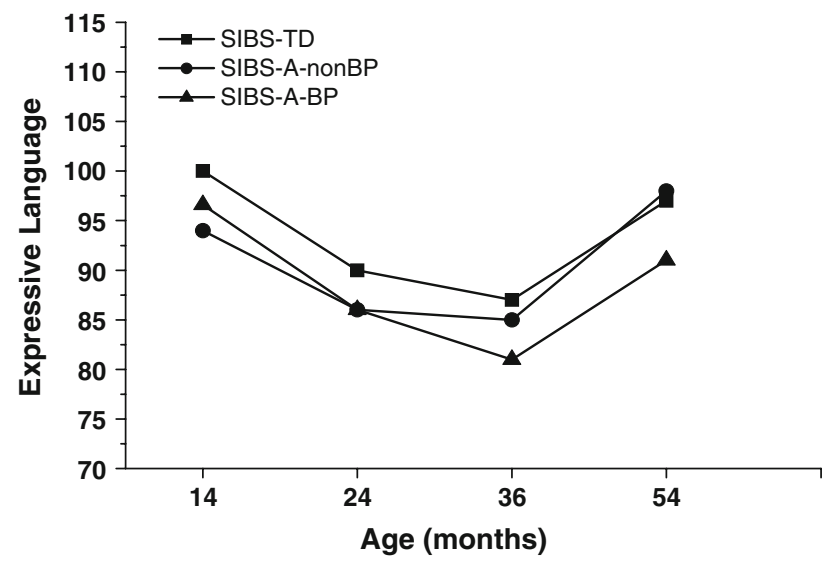

Fig. 12 Expressive language based on test scores only (Model 3)

We identified three groups at age 7 years (SIBS-A-BP, SIBS-A-nonBP, and SIBS-TD) and "looked back" at their cognitive and language developmental trajectories in the preschool years (4-54 months) using growth curve analysis. Regarding cognition, although SIBS-A identified at age 7 years with BAP-related difficulties in cognition and language had manifested lower cognitive scores at the preschool years (an average of 7-10 DQ/IQ points) than their SIBS-TD counterparts, the resultant growth curves yielded no significant differences, and their growth curves over time were similar in shape and parallel, indicating a similar rate of developmental change.

The language scores of SIBS-A-BP identified by both parental report and test scores and only by parental report at 7 years were significantly lower (on average by 10-21 points) compared to the language scores of the SIBS-TD throughout the preschool years. Furthermore, SIBS-A-BP identified by parental reports at 7 years had significantly lower language scores (on average by about 16 points) compared not only to the SIBS-TD but also to the SIBS-AnonBP, and they also revealed a different rate of change than the other two groups. Furthermore, the language scores of SIBS-A-nonBP, based on test scores at age 7 years, were significantly lower (on average by 9 points) compared to 7-year-old SIBS-TD and had a different rate of change from 14 to 54 months.

Our findings suggest the importance of using parental reports for identifying BAP-related difficulties at 7 years. Different sources of information at 7 years (e.g., parental reports and/or test scores) yielded different results regarding early language development, thus indicating the importance of using both kinds of measures. Interestingly, parental reports of BAP-related difficulties at 7 years were the best method in revealing early language difficulties from 14 to 54 months.

Finally, this study although unique in its longitudinal rather than cross sectional approach, suffers from some shortcomings, such as the relatively small sample size and the resulting small subgroups; the lack of additional comparison groups, such as a group of siblings of children with learning disorders or language delays; and the fact that our sample is not entirely a representative one. Regarding the validity of adding parents report in addition to test results at age 7 year, there is a possibility that the reports of parents of children with autism regarding their unaffected sibling might be biased in both directions of maximizing or minimizing their child's difficulties, because of having the child with autism as a reference. This bias is unlikely to be manifested in the SIBS-TD group. Finally, in any longitudinal study, finding measures that are valid across time points is somewhat difficult as it evident by our use of various tests at various ages. However, at each time point we carefully choose the best instrument available and whichever bias that may have been operating-affected both groups. These issues remain to be investigated more in depth in future studies with larger samples and additional comparison groups. Not withstanding these limitations, the current study highlights language as an area of concern for some younger siblings of children with autism spectrum disorder. Thus, it may be that enough data have now 
accumulated to merit consideration of early intervention programs and intervention studies for these children.

Acknowledgments This study was supported by the United StatesIsrael Binational Science Foundation (BSF), grant numbers 94-66/3 and 97-00073, awarded to NY and MS, and by Autism Speaks, grant number \#993, awarded to NY. We are grateful to the families who took part for their cooperation and to Dee Ankonina for her editorial assistance.

Open Access This article is distributed under the terms of the Creative Commons Attribution Noncommercial License which permits any noncommercial use, distribution, and reproduction in any medium, provided the original author(s) and source are credited.

\section{References}

August, G. J., Stewart, M. A., \& Tsai, L. (1981). The incidence of cognitive disabilities in the siblings of autistic children. The British Journal of Psychiatry, 13, 416-422. doi:10.1192/bjp.138. 5.416 .

Bailey, A., Palferman, S., Heavey, L., \& Le Couteur, A. (1998). Autism: The phenotype in relatives. Journal of Autism and Developmental Disorders, 28, 369-392. doi:10.1023/A:102604 8320785.

Bates, J. E., Freeland, C. A., \& Lounsbury, M. L. (1979). Measurement of infant difficultness. Child Development, 50, 794-803. doi:10.2307/1128946.

Bauminger, N., \& Yirmiya, N. (2001). The functioning and wellbeing of SIBS-A: Behavioral-genetic and familial contributions. In J. A. Burack, T. Charman, N. Yirmiya, \& P. R. Zelazo (Eds.), The development of autism: Perspectives from theory and research (pp. 61-80). Mahwah: Erlbaum.

Bayley, N. (1993). Bayley scales of infant development (2nd ed.). San Antonio: Psychological Corporation.

Bishop, D. V. M., Maybery, M., Wong, D., Maley, A., \& Hallmayer, J. (2006). Characteristics of the broader phenotype in autism: A study of siblings using the children's communication checklist-2. American Journal of Medical Genetics. Part B, Neuropsychiatric Genetics, 128B, 54-60.

Bishop, D. V. M., Maybery, M., Wong, D., Maley, A., Hill, H., \& Hallmayer, J. (2004). Are phonological processing deficits part of the broad autism phenotype? American Journal of Medical Genetics Part B, Neuropsychiatric Genetics, 141B, 117-122. doi:10.1002/ajmg.b.30267.

Bolton, P., Macdonald, H., Pickles, A., Rios, P., Goode, S., Crowson, M., et al. (1994). A case-control family history study of autism. Journal of Child Psychology and Psychiatry and Allied Disciplines, 35, 877-900. doi:10.1111/j.1469-7610.1994.tb02300.x.

Boutin, P., Maziade, M., Merette, C., Mondor, M., Bedard, C., \& Thivierge, J. (1997). Family history of cognitive disabilities in first-degree relatives of autistic and mentally retarded children. Journal of Autism and Developmental Disorders, 27, 165-176. doi:10.1023/A:1025891824269.

Bryson, S. E., Zwaigenbaum, L., Brian, J., Roberts, W., Szatmari, P., Rombough, V., et al. (2007). A prospective case series of high-risk infants who developed autism. Journal of Autism and Developmental Disorders, 37, 12-24. doi:10.1007/s10803-006-0328-2.

Cassel, T. D., Messinger, D. S., Ibanez, L. V., Haltigan, J. D., Acosta, S. I., \& Buchman, A. C. (2007). Early social and emotional communication in the infant siblings of children with autism spectrum disorders: An examination of the broad phenotype.
Journal of Autism and Developmental Disorders, 37, 122-132. doi:10.1007/s10803-006-0337-1.

Constantino, J. N., \& Todd, R. D. (2005). Intergenerational transmission of subthreshold autistic traits in the general population. Biological Psychiatry, 57, 655-660.

Dawson, G., Estes, A., Munson, J., Schellenberg, G., Bernier, R., \& Abbott, R. (2007). Quantitative assessment of autism symptomrelated traits in probands and parents: Broader phenotype autism symptom scale. Journal of Autism and Developmental Disorders, 37, 523-536. doi:10.1007/s10803-006-0182-2.

Delorme, R., Gousse, V., Roy, I., Trandafir, A., Mathieu, F., MourenSimeoni, M. C., et al. (2007). Shared executive dysfunctions in unaffected relatives of patients with autism and obsessivecompulsive disorder. European Psychiatry, 22, 32-38. doi: 10.1016/j.eurpsy.2006.05.002.

Dorris, L., Espie, C. A. E., Knott, F., \& Salt, J. (2004). Mind-reading difficulties in the siblings of people with Asperger's syndrome: Evidence for a genetic influence in the abnormal development of a specific cognitive domain. Journal of Child Psychology and Psychiatry and Allied Disciplines, 45, 412-418. doi:10.1111/ j.1469-7610.2004.00232.x.

Elder, L. M., Dawson, G., Toth, K., Fein, D., \& Munson, J. (2008). Head circumference as an early predictor of autism symptoms in younger siblings of children with autism spectrum disorder. Journal of Autism and Developmental Disorders, 38, 11041111. doi:10.1007/s10803-007-0495-9.

Elsabbagh, M., \& Johnson, M. H. (2007). Infancy and autism: Progress, prospects, and challenges. In C. von Hofsten \& K. Rosander (Eds.), Progress in brain research (Vol. 164) (pp. 355383). Amsterdam: Elsevier.

Folstein, S. E., Santangelo, S. L., Gilman, S. E., Piven, J., Landa, R., Lainhart, J., et al. (1999). Predictors of cognitive test patterns in autism families. Journal of Child Psychology and Psychiatry and Allied Disciplines, 40, 1117-1128. doi:10.1111/1469-7610. 00528.

Fombonne, E., Bolton, P., Prior, J., Jordan, H., \& Rutter, M. (1997). A family study of autism: Cognitive patterns and levels in parents and siblings. Journal of Child Psychology and Psychiatry and Allied Disciplines, 38, 667-683. doi:10.1111/j.1469-7610.1997. tb01694.x.

Gamliel, I., Yirmiya, N., \& Sigman, M. (2007). The development of young siblings of children with autism from 4 to 54 months. Journal of Autism and Developmental Disorders, 37, 171-183. doi:10.1007/s10803-006-0341-5.

Gillberg, C., Gillberg, I. C., \& Steffenburg, S. (1992). Siblings and parents of children with autism: A controlled population-based study. Developmental Medicine and Child Neurology, 34, 389-398.

Happé, F., Briksman, J., \& Frith, U. (2001). Exploring the cognitive phenotype of autism: Weak "central coherence" in parents and siblings of children with autism. Vol. I. Experimental tests. Journal of Child Psychology and Psychiatry and Allied Disciplines, 42, 299-307. doi:10.1111/1469-7610.00723.

Hughes, C., Plumet, M. H., \& Leboyer, M. (1999). Towards a cognitive phenotype for autism: Increased prevalence of executive dysfunction and superior spatial span amongst siblings of children with autism. Journal of Child Psychology and Psychiatry and Allied Disciplines, 40, 705-718. doi:10.1111/14697610.00487.

Hurley, R. S. E., Losh, M., Parlier, M., Reznick, J. S., \& Piven, J. (2007). The broad autism phenotype questionnaire. Journal of Autism and Developmental Disorders, 37, 1679-1690.

Jastak, S., \& Wilkinson, G. (1993). The wide range achievement test-(WRAT-III) (3rd ed.). Wilmington: Jastak.

Kaufman, A. S., \& Kaufman, N. L. (1983). Kaufman assessment battery for children $(K-A B C)$. Circle Pines: AGS. 
Kristjansson, S. D., Kircher, J. C., \& Webb, A. K. (2007). Multilevel models for repeated measures research designs in psychophysiology: An introduction to growth curve modeling. Psychophysiology, 44, 728-736. doi:10.1111/j.1469-8986.2007.00544.x.

Lainhart, J. E. (1999). Psychiatric problems in individuals with autism, their parents and siblings. International Review of Psychiatry (Abingdon, England), 11, 278-298. doi:10.1080/ 09540269974177.

Landa, R., \& Garrett-Mayer, B. (2006). Development in infants with autism spectrum disorders: A prospective study. Journal of Child Psychology and Psychiatry and Allied Disciplines, 47, 629-638. doi:10.1111/j.1469-7610.2006.01531.x.

Landa, R. J., Holman, K. C., \& Garrett-Mayer, E. (2007). Social and communication development in toddlers with early and later diagnosis of autism spectrum disorders. Archives of General Psychiatry, 64, 853-864. doi:10.1001/archpsyc.64.7.853.

Leboyer, M., Plumet, M. H., Goldblum, M. C., Perez-Diaz, F., \& Marchaland, C. (1995). Verbal versus visuospatial abilities in relatives of autistic females. Developmental Neuropsychology, $11,139-155$.

Loh, A., Soman, T., Brian, J., Bryson, S. E., Roberts, W., Szatmari, P., et al. (2007). Stereotyped motor behaviors associated with autism in high-risk infants: A pilot videotape analysis of a sibling sample. Journal of Autism and Developmental Disorders, 37, 25-36. doi:10.1007/s10803-006-0333-5.

Lord, C., Risi, S., Lambrecht, L., Cook, E. H., Leventhal, B. L., DiLavore, P. C., et al. (2000). The autism diagnostic observation schedule-generic: A standard measure of social and communication deficits associated with the spectrum of autism. Journal of Autism and Developmental Disorders, 30, 205-223. doi:10.1023/ A:1005592401947.

Merin, N., Young, G. S., Ozonoff, S., \& Rogers, S. J. (2007). Visual fixation patterns during reciprocal social interaction distinguish a subgroup of 6-month-old infants at-risk for autism from comparison infants. Journal of Autism and Developmental Disorders, 37, 108-121. doi:10.1007/s10803-006-0342-4.

Orsmond, G. I., \& Seltzer, M. M. (2007). Siblings of individuals with autism spectrum disorders across the life course. Mental Retardation and Developmental Disabilities Research Reviews, 13, 313-320. doi:10.1002/mrdd.20171.

Ozonoff, S., Rogers, S. J., Farnham, J. M., \& Pennington, B. F. (1993). Can standard measures identify subclinical markers of autism? Journal of Autism and Developmental Disorders, 23, 429-441. doi:10.1007/BF01046049.

Pilowsky, T., Yirmiya, N., Shalev, R., \& Gross-Tsur, V. (2003). Language abilities of siblings of children with autism. Journal of Child Psychology and Psychiatry and Allied Disciplines, 44, 914-925. doi:10.1111/1469-7610.00175.

Pilowsky, T., Yirmiya, N., Shalev, R., \& Gross-Tzur, V. (2007). Neuropsychological functioning of siblings of children with autism, siblings of children with developmental language delay, and siblings of children with mental retardation of unknown genetic etiology. Journal of Autism and Developmental Disorders, 37, 537-552. doi:10.1007/s10803-006-0185-z.

Piven, J. (1999). Genetic liability for autism: The behavioral expressions in relatives. International Review of Psychiatry (Abingdon, England), 11, 299-308. doi:10.1080/09540269974186.

Piven, J., Gayle, J., Chase, G. A., Fink, B., Landa, R., Wzorek, M. M., et al. (1990). A family history study of neuropsychiatric disorders in the adult siblings of autistic individuals. Journal of the American Academy of Child and Adolescent Psychiatry, 29, 177-183. doi:10.1097/00004583-199003000-00004.

Piven, J., \& Palmer, P. (1997). Cognitive deficits in parents from multiple-incidence autism families. The American Journal of Psychiatry, 156, 557-563.
Plumet, M. H., Goldblum, M. C., \& Leboyer, M. (1995). Verbal skills in relatives of autistic females. Cortex, 31, 723-733.

Presmanes, A. G., Walden, T. A., Stone, W. A., \& Yoder, P. J. (2007). Effects of different attentional cues on responding to joint attention in younger siblings of children with autism spectrum disorders. Journal of Autism and Developmental Disorders, 37, 133-144. doi:10.1007/s10803-006-0338-0.

Reynell, J. K., \& Grubber, C. P. (1990). Reynell developmental language scale. Los Angeles: Western Psychological Association.

Rutter, M., Le Couteur, A., \& Lord, C. (2003). ADI-R: The autism diagnostic interview-revised. Los Angeles: Western Psychological Services.

Schuntermann, P. (2007). The sibling experience: Growing up with a child who has pervasive developmental disorder or mental retardation. Harvard Review of Psychiatry, 15, 93-108. doi:10.1080/10673220701432188.

Semel, E., Wiig, E. H., \& Secord, W. A. (1995). Clinical evaluation and language fundamentals (CELF) (3rd ed.). San Antonio: Psychological Corporation/Harcourt Brace.

Shaked, M., Gamliel, I., \& Yirmiya, N. (2006). Theory of mind abilities in young siblings of children with autism. Autism, 10, 173-187. doi:10.1177/1362361306062023.

Singer, J. D., \& Willett, J. B. (2003). Applied longitudinal data analysis: Modeling change and event occurrence. New York: Oxford University Press.

Smalley, S. L., \& Asarnow, R. F. (1990). Brief report: Cognitive subclinical markers in autism. Journal of Autism and Developmental Disorders, 20, 271-278. doi:10.1007/BF02284724.

Stone, W. L., McMahon, C. R., Yoder, P. J., \& Walden, T. A. (2007). Early social-communicative and cognitive development of younger siblings of children with autism spectrum disorders. Archives of Pediatrics and Adolescent Medicine, 161, 384-390. doi:10.1001/archpedi.161.4.384.

Sullivan, M., Finelli, J., Marvin, A., Garrett-Mayer, E., Bauman, M., \& Landa, R. (2007). Response to joint attention in toddlers at risk for autism spectrum disorder: A prospective study. Journal of Autism and Developmental Disorders, 37, 37-48. doi:10.1007/ s10803-006-0335-3.

Toth, K., Dawson, J., Meltzoff, A. N., Greenson, J., \& Fein, D. (2007). Early social, imitation, play, and language abilities of young non-autistic siblings of children with autism. Journal of Autism and Developmental Disorders, 37, 145-157. doi:10.1007/ s10803-006-0336-2.

Wechsler, D. (1991). Wechsler intelligence scale for children-(WISCIII) (3rd ed.). San Antonio: Psychological Corporation.

Wiig, E. H., Secord, W., \& Semel, E. (1992). CELF-preschool: Clinical evaluation of language fundamentals- preschool version. San Antonio: Psychological Corporation.

Wong, D., Maybery, M., Bishop, D. V., Maley, A., \& Hallmayer, J. (2006). Profiles of executive function in parents and siblings of individuals with autism spectrum disorders. Genes Brain \& Behavior, 8, 561-576. doi:10.1111/j.1601-183X.2005.00199.x.

Yirmiya, N., Gamliel, I., Pilowsky, T., Feldman, R., Baron-Cohen, S., \& Sigman, M. (2006). The development of siblings of children with autism at 4 and 14 months: Social engagement, communication and cognition. Journal of Child Psychology and Psychiatry and Allied Disciplines, 47, 511-523. doi:10.1111/ j.1469-7610.2005.01528.x.

Yirmiya, N., Gamliel, I., Shaked, M., \& Sigman, M. (2007). Cognitive and verbal abilities in 24- to 36-month-old siblings of children with autism. Journal of Autism and Developmental Disorders, 37, 218-229. doi:10.1007/s10803-006-0163-5.

Yirmiya, N., \& Ozonoff, S. (2007). The very early autism phenotype. Journal of Autism and Developmental Disorders, 37, 1-11. doi:10.1007/s10803-006-0329-1. 
Yirmiya, N., Shaked, M., \& Erel, O. (2001). Comparing siblings of individuals with autism and siblings of individuals with other diagnoses: An empirical summary. In E. Schopler, N. Yirmiya, C. Shulman, \& L. Marcus (Eds.), The research basis for autism intervention (pp. 59-73). New York: Plenum.

Zwaigenbaum, L., Bryson, S., Rogers, T., Roberts, W., Brian, J., \& Szatmari, P. (2005). Behavioral manifestations of autism in the first year of life. International Journal of Developmental Neuroscience, 23, 143-152. doi:10.1016/j.ijdevneu.2004.05.001. Zwaigenbaum, L., Stone, W. L., Dobkins, K., Urbano, R., Lambert, W., Bryson, S., et al. (2008, May). Prospective evaluation of head growth in infants at increased risk of autism. Paper presented at the International Meeting for Autism Research, London. 